\title{
THE EFFECT OF THE OPERATING CONDITIONS ON THE APPARENT VISCOSITY OF CRUDE PALM OIL DURING OIL CLARIFICATION
}

\author{
Sulaiman Al-ZuhaIR* ${ }^{*}$ Mirghani I. AHMED ${ }^{\ddagger *}$ AND Yousif A. ABAKR \\ * School of Engineering, Taylor's College, Subang Jaya, Malaysia. \\ * Department of Mechanical Engineering, International Islamic University, Malaysia. \\ e-mail:mirghani@iiu.edu.my
}

\begin{abstract}
This paper discusses the apparent viscosity of crude palm oil, using rotary viscometer, under different boundary conditions. It was experimentally shown that the apparent viscosity of palm oil drops with increasing of the shear rate and the temperature. However, the effect of temperature on the viscosity tends to fade at temperatures beyond $80{ }^{\circ} \mathrm{C}$. A correlation between the apparent viscosity of crude palm oil and the operating conditions was developed. This correlation can be used in design of crude palm oil settlers and in determining the optimum operating conditions.
\end{abstract}

Key Words: Crude palm oil, apparent viscosity, shear rate, modelling, separation

\section{INTRODUCTION}

The raw palm oil as pressed from the fruits is a product even cruder than the commercial crude palm oil. It contains a lot of fibres, dirt, water, soluble impurities and considerable amount of debris. The average composition (volume to volume) of the raw palm oil as received from the screw press is $40-75 \%$ oil, $10-40 \%$ water and $6-25 \%$ nonorganic solids [1]. The crude palm oil is left in a clarifier to allow for the separation of oil from water (together with most of the debris). Water and its content of debris form immiscible liquids with the oil. The heavier water and debris settle to the bottom leaving the relatively clean and light oil on the top to be skimmed off later.

Previous studies found that a lot of oil is lost in the settler and most of the waste water is produced there. It is very important to determine the optimum design parameters of crude palm oil settler. The separation of clear oil droplets from crude palm oil mixture is treated as a coalescence process [2-4], with oil droplets rising upward. To determine the

* Corresponding author 
optimum design parameters of crude palm oil settler, it is essential to determine the rising velocity of oil droplets in the aqueous phase. There are two main factors affecting the rising velocity, namely, density and viscosity [2]. The effect of the operating conditions, such as temperature and shear rate on the density is relatively small compared to their effect on viscosity [5-7]. Hence, the density may be treated as a constant and the viscosity is considered the main operating condition influencing the separation process. Regardless of the numerous research conducted previously, a reliable model to predict the effect of the independent operating conditions on the viscosity of crude palm oil is still lacking.This is due to the difficulty in studying crude palm oil, which behaves as a non-Newtonian fluid [1], and also due to the composition complexity of the mixture itself (oil, water and debris). The fact is that, in all previous works to determine the design equations of crude palm oil settlers, the viscosity of crude palm oil mixture was always assumed, incorrectly, to be an additional variable, independent of temperature and shear rate $[1,6]$.

In this study, a correlation between viscosity and the independent operating conditions affecting it will be formulated (i.e., temperature and shear rate). This correlation will be employed into the design Eqs. of crude palm oil settlers, and will be used to determine the optimum operation conditions. The proposed correlation will reflect the combined effects of both shear rate and temperature.

\section{THE MATHEMATICAL MODEL}

Previous experimental work proved that crude palm oil is a non-Newtonian fluid. The apparent viscosity was shown to change with shear rate applied. The power law, Eq. (1), is widely used in the literature to express the effect of shear rate on the viscosity of nonNewtonian liquids at constant temperature [8-10],

$$
\mu_{\alpha}=k \gamma^{\mathrm{n}-1}
$$

The apparent viscosity of crude palm oil was found to decrease with shear rate [1], this behaviour is called shear thinning, which is characterised by the value of the power index $n$ being less than unity.

On the other hand, temperature changes also affect the apparent viscosity of crude palm oil. Like any other liquid, the apparent viscosity of crude palm oil is expected to reduce as temperature increases. This phenomenon is explained by the reduction of the intermolecular attractions with increasing temperature. In this work the effect of temperature on the apparent viscosity of non-Newtonian liquids at constant shear rate is expressed using Arrhenius expression [8],

$$
\mu_{\alpha}=a_{\alpha} \mathrm{e}^{\left(E_{a v} / R T\right)}
$$

Equations (1) and (2) describe the separate effects of either shear rate or temperature, however, it is desired to have an Eq. that combines both effects (shear rate and temperature) in one model Eq. that can be used in the design Eq.s of crude palm oil settlers. McCabe et al [11] derived an expression that combines the effects of the shear rate and the temperature by combining Eqs. 1 and 2, 


$$
\mu_{a}=k_{o}(\gamma)^{\bar{n}-1} e^{\left[\frac{E_{a v}}{R_{g} T}\right]}
$$

The constants found in Eq (3) can now be determined experimentally.

\section{MATERIALS AND METHOD}

\subsection{Materials}

Screened crude palm oil samples were obtained from Dengkil mill, Malaysia, and diluted with $40 \%$ (vol/vol) water to simulate the mixture that enters the crude palm oil settler in the mill.

\subsection{Apparatus}

There are many methods to measure the apparent viscosity of non-Newtonian fluids [11]. The apparatus used in this study is rotary viscometer (Cannon $2020 \mathrm{LV}$, viscosity range 0.001 to $2000 \mathrm{~Pa} \mathrm{sec}$, with accuracy of $\pm 1 \%$ ) in which a motor with variable speed drives a spindle immersing in the sample to be investigated with a spiral spring. The viscosity of the sample generates a resisting torque at the spindle, which can be measured with the aid of the torsion of the spiral spring and through a computer software. The shear stress can be calculated for different shear rates. The computer software is also used to calculate the apparent viscosity from the measured values of shear stress at various shear rates. A water jacket, with circulating temperature-controlled water, surrounds the sample pot to control the temperature. Different shear rates were obtained by changing the size and the speed of the spindle. Figure 1 shows the apparatus used.

\subsection{Methodology}

A sample of $25 \mathrm{ml}$ volume was contained in the sample pot each time. The temperature of the sample was controlled by adjusting the temperature of the circulating water in the jacket. Measurements were carried out for the changes of the apparent viscosity with shear rate at five different temperatures $40{ }^{\circ} \mathrm{C}, 50{ }^{\circ} \mathrm{C}, 60^{\circ} \mathrm{C}, 70{ }^{\circ} \mathrm{C}$ and $80^{\circ} \mathrm{C}$.

\section{RESULTS AND DISCUSSIONS}

The measured apparent viscosity at different temperatures and different shear rates are shown in Fig. 2. It can be clearly seen that the crude palm oil mixture is a shear thinning fluid, as the viscosity decreases with the increase in shear rate. It can be also seen from Fig. 2. that the apparent viscosity decreases with increasing the temperature, which is the case for all liquids, since the intermolecular attraction decreases with increasing temperature. 


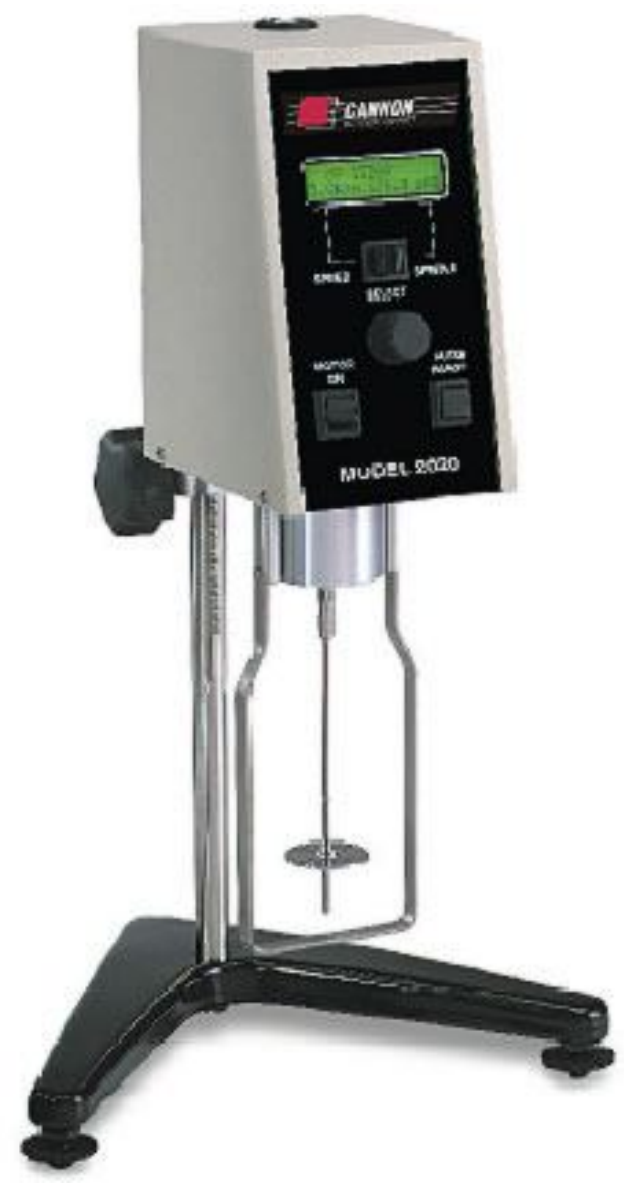

Fig. 1: The rotary viscometer (Cannon 2020 LV).

The natural logarithmic of $\mu_{a}$ was drawn against the natural logarithmic of $\gamma$ at five different temperatures and the results are shown in Fig. 3. It can be clearly seen that the straight lines generated are almost parallel with identical slopes, which validates the proposed model. The values of $n-1$ at each temperature were determined from the slopes of the straight lines in Fig. 3. The average value of $n$ was then calculated as 0.4 with standard deviation of \pm 0.036 , which indicates a deviation of less that $10 \%$.

To determine the activation energy, $\ln \left(\mu_{a} / \gamma^{\bar{n}-1}\right)$ was plotted against $(1 / T)$, and $\left(E_{a v} / R\right)$, and $\ln (k)$ were determined from the slope and the intercept, respectively of the straight line generated (Fig. 4) as predicted from Eq (3). From the slope of the straight line in Fig. 4., $E_{a v} / R=1511.6 k^{-1}$, and from the intercept, $k=3.5 \times 10^{-3}$. The standard deviations of the results were low and in the range of 0.020 to 0.058 , and presented in the error bars found in Fig 4. 


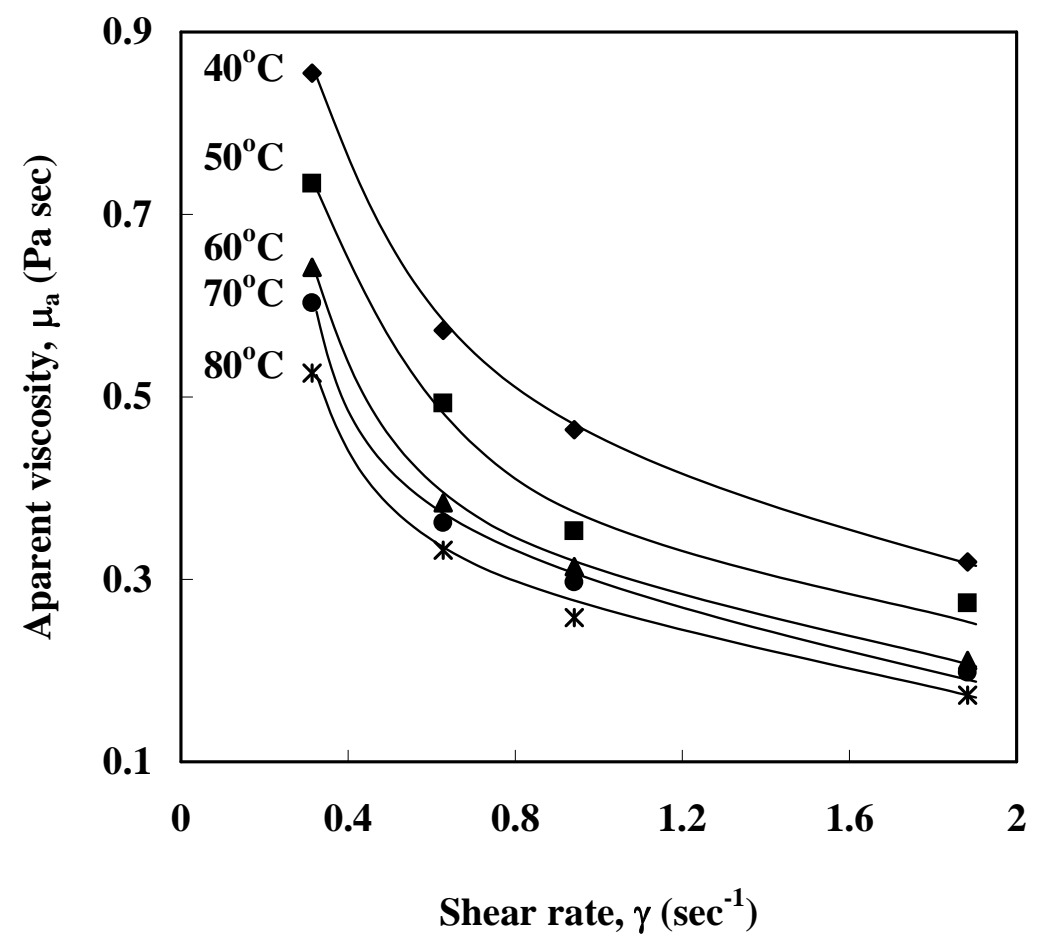

Fig. 2: The effect of temperature and shear rate on the apparent viscosity of crude palm oil.

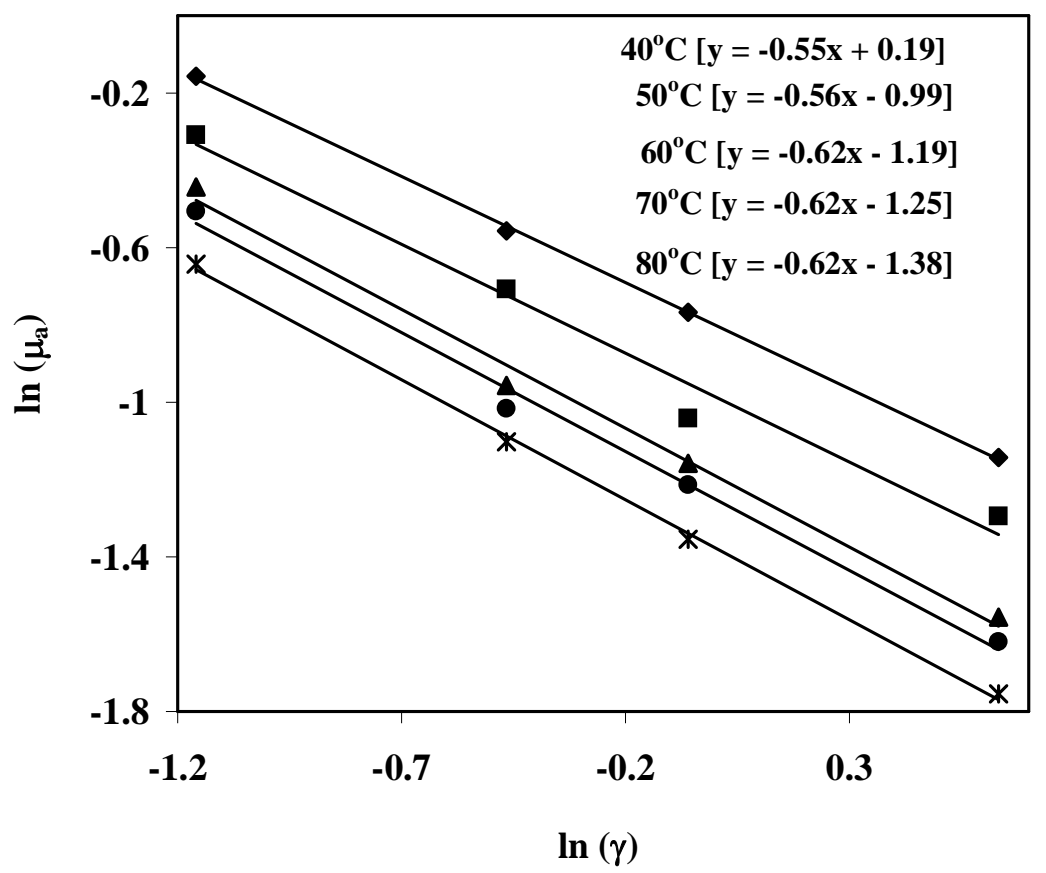

Fig. 3: The variation of $\ln \left(\mu_{a}\right)$ with $\ln (\gamma)$ at different temperatures. 


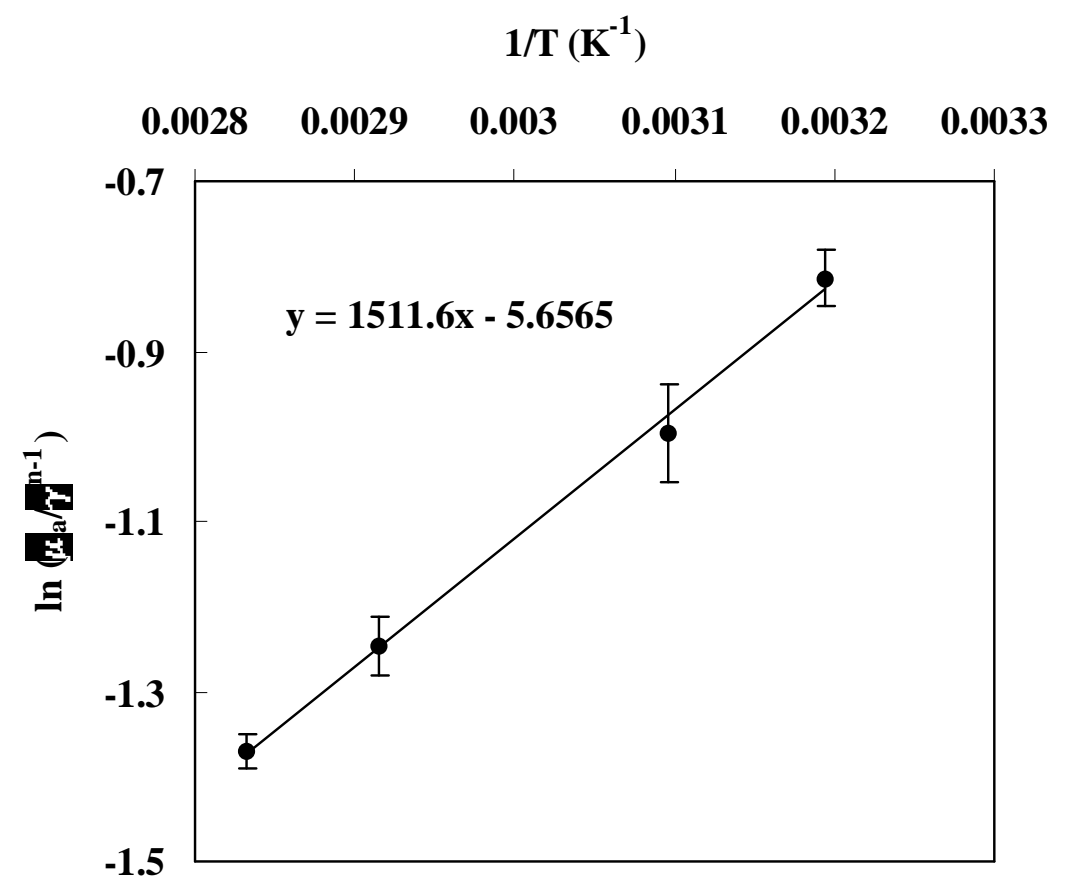

Fig. 4: $\operatorname{Ln}\left(\mu_{\mathrm{a}} / \gamma^{\mathrm{n}-1}\right)$ versus $1 / \mathrm{T}$

The correlation between the apparent viscosity of crude palm oil and the operating conditions, including the shear rate and temperature is therefore,

$$
\mu_{\alpha}=3.5 \times 10^{-3} \exp \left(\frac{1511.6}{T}\right) \gamma^{0.6} \pm 0.02
$$

Fig. 5 shows the comparison between the experimental results and the proposed model curves that were based on Eq (4), for three different temperatures (40, 60 and $80{ }^{\circ} \mathrm{C}$ ). It can be noted that the model predicts fairly well the apparent viscosity at various shear rates for all three temperatures.

The apparent viscosity correlation, Eq. (4), can be introduced directly into any design Eq. of crude palm oil settler, instead of keeping the viscosity as an additional variable and can be used to determine the optimum operating temperature. The rate of separation of crude palm oil increases as the viscosity decreases, hence, the temperature and the shear rate should be increased. The increase in temperature is always favourable for increasing the rate of oil separation, and crude palm oil settlers should be designed to operate under high temperatures, however, energy consumption and equipment materials costs should be considered. Furthermore, it can be seen from Fig. 6 that the effect of temperature on the viscosity tends to fade at temperatures beyond $80{ }^{\circ} \mathrm{C}$, so increasing the temperature beyond this point, in addition to the energy consumption and material cost stresses, will not result in substantial decrease in the viscosity to justify this increase. On the other hand, 
increasing the shear rate, although results in reducing the viscosity, enhances the dispersion of oil, but it is not advisable to increase it by agitation or by any other means.

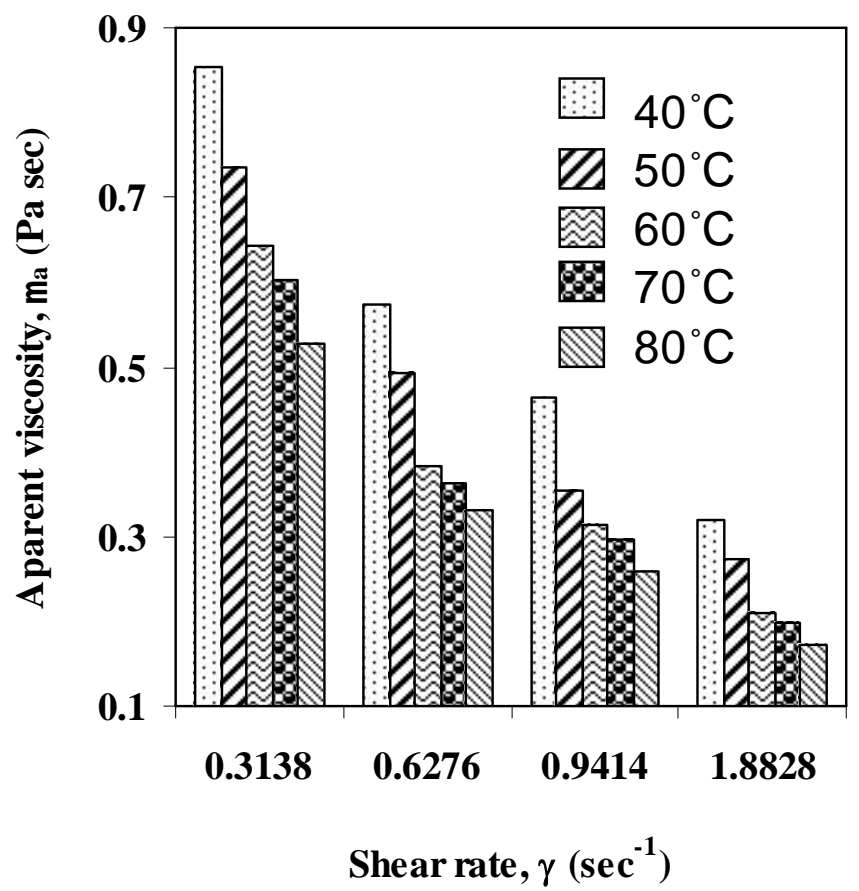

Fig. 5: Comparison between experimental results and the proposed model curves showing the effect of agitation speed on the apparent viscosity at three different temperatures $\left(40,60\right.$ and $\left.80{ }^{\circ} \mathrm{C}\right)$

Figure 6 shows the combined effect of the shear rate and the temperature on the apparent viscousity of crude palm oil. This figure is a graphical presentation of Eq. (4), where the effects of two parameters are both presented on the same graph. 


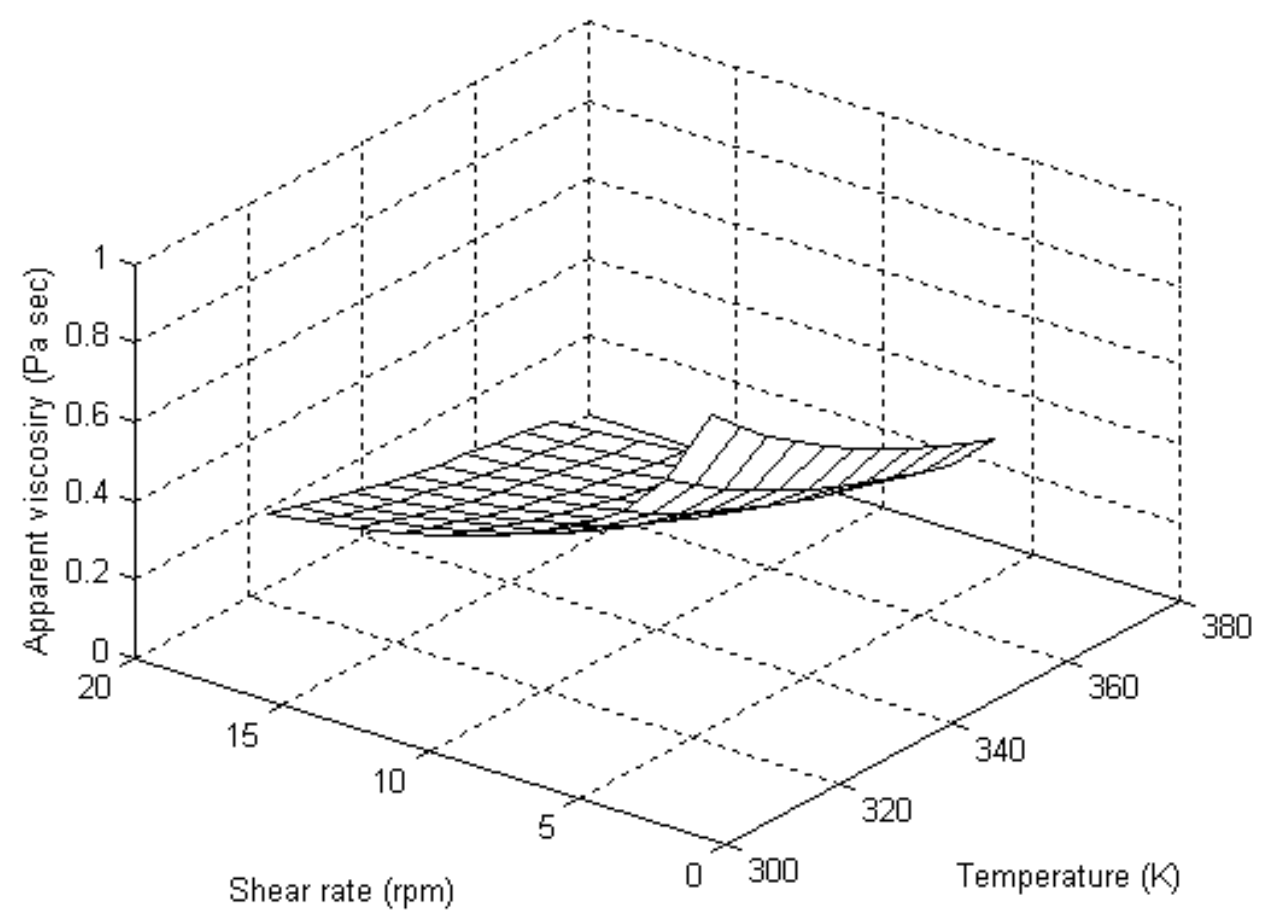

Fig. 6: The combined effects of temperature and shear rate on the apparent viscosity.

\section{CONCLUSION}

Analytical and experimental studies of the behaviour of the crude palm oil in the palm oil settlers were conducted. A correlation between the apparent viscosity of crude palm oil and the operating conditions, has been determined. The results showed a good agreement between the experimental results and the estimated values of the obtained correlation. The new correlation reflects accurately the combined effects of both shear rate and temperature on the apparent viscosity of crude palm oil. This correlation can be employed into the design of crude palm oil settlers, and can be used also to determine the optimum operation conditions for palm oil settlers.

\section{REFERENCES}

[1] K.H Lim. and D.A.M Whiting, The Influence of Non-Newtonian Behaviour of Crude Palm Oil on the Design of the Clarification Station Equipment. The Proceedings of The Malaysian International Symposium on Palm Oil Proceedings and Marketing, International Developments in Palm Oil. Malaysia, 1977.

[2] E. Barnea, and J. Mizrahi, Separation Mechanism of Liquid/liquid Dispersion in Deep layer Gravity Settler, Part I, PartII, Part III, and Part IV. Trans. Inst. Chem. Eng., Vol. 53, pp. 6192, 1975. 
[3] S. Hartland, and S.A.K. Jeelani, Choice of Model for Predicting the Dispersion Height in Liquid-liquid Gravity Settlers from Batch Settling Data. Chem. Eng. Science, Vol. 42, No. 8, pp. 1927-1938, 1978.

[4] A. Fasano, The Dynamics of Two-Phase Liquid Dispersions: Necessity of a New Approach, Milan Journal of Mathematics, Vol. 70, No. 1, pp. 245-264, 2002.

[5] B. Marcia, S. Günter, J.S. Milan, O.A. Elseoud, Vegetable Oils-Based Microemulsions: Formation, Properties, and Application for "ex-situ" Soil Decontamination, Colloid Polym Sci, Vol. 280, pp. 973-983, 2002.

[6] K.H. Lim, Theory and Application of Clarification in Palm Oil Mills. Harrisons and Crosfield (M) Sdn. Bhd. Malaysia 1982.

[7] PORIM. Data Sheet for Engineers. E. Engineering News 1987.

[8] N. Aksel, A Model for the Bulk Viscosity of a Non-Newtonian Fluid, Continuum Mechanics and Thermodynamics, Vol. 7, No 3, pp. 333-339, 2002.

[9] B.R. Munson, D.F. Young and T.H. Okishi, Fundamentals of Fluid Mechanics, third ed., John Wiley \& Sons Inc., New York. 1998.

[10] G.B. Wallis, One-Dimensional Two-Phase Flow, McGraw-Hill, New York. 1969.

[11] W.L. McCabe, J.C. Smith and P. Harrott, Unit Operations of Chemical Engineering. 5th edition. McGraw Hill Inc., New York. 1993.

[12] N.A. Park, T.F. Irvine, An alternative method of simultaneously measuring viscosity and density of Newtonian and power-law fluids using the falling needle viscometer. Proc. Of the XIIIth international congress of rheology, Cambridge, UK, Vol. 3, pp. 140-142, 2002.

\section{NOMENCLATURE}

$\begin{array}{ll}a_{a} & \text { Constant defined by Eq. (2) (Pa sec) } \\ E_{a v} & \text { Activation energy }\left(\mathrm{J} \mathrm{mol}^{-1}\right) \\ k & \text { Constant defined by Eq (1) } \\ k_{o} & \text { Constant defined by Eq (3) } \\ n & \text { Constant defined by Eq (1) } \\ \bar{n} & \text { The average value of the measured } n \\ R & \text { Universal gas constant }\left(\mathrm{J}^{-1} \mathrm{~K}^{-1}\right) \\ T & \text { Temperature }(\mathrm{K})\end{array}$

Greek letters

$\begin{array}{ll}\gamma & \text { Shear rate }\left(\mathrm{sec}^{-1}\right) \\ \mu_{\alpha} & \text { Apparent viscosity (Pa sec) }\end{array}$




\section{BIOGRAPHIES}

Sulaiman Al-Zuhair received his B.Sc. in Chemical Engineering from Jordan University of Science and Technology in 1996, M.Sc. in Chemical and Environmental Engineering from University Putra Malaysia in 1998, and Ph.D. in Biochemical Engineering from University of Malaya in 2003. At present, Dr. Al-Zuhair works as a Chemical Engineering lecturer at Taylor's College, Subang Jaya, Malaysia.

Mirghani I. Ahmed was born in Singa, Sudan in 1956. He received his M.Sc. and Ph.D. in Mechanical Engineering from Budapest Technical University, Hungary in 1987. He worked with the Sudan University of Science and Technology as Asst. Prof. from 19871989. He worked with IBM - Canada as Research Associate from 1989 - 1996. He is currently an Associate Professor at the department of Mechanical Engineering, International Islamic University Malaysia (IIUM). Dr. Ahmed's primary research interests are renewable energy, thermal comfort problems, electronic component cooling, modeling and simulation, computational fluid dynamics applications and heat transfer.

Yousif A. Abakr received his B.Sc. and M.Sc. in Mechanical Engineering from University of Khartoum. He worked as a Mechanical Engineering lecturer at Sudan University of Science and Technology, 1995 - 1997. Currently, he is a Ph.D. student at the International Islamic University, Malaysia. 